\title{
Novel Printed H-Antenna with Slot and Parasitic Element for RFID Systems
}

\author{
A.Bendali ${ }^{1}$, A. Attalhaoui ${ }^{2}$, S. Bri ${ }^{3}$, M. Habibi ${ }^{4}$, A. El fellahi ${ }^{5}$ \\ ${ }^{1,2,4}$ Laboratory of Electronic System, Information Processing, Mechanics and Energetic (ESIPME), Faculty of \\ Sciences, Ibn tofail, Morocco, \\ abdelhak.bendali@hotmail.com, mohamed.habibi@hotmail.com, abdellah-3@hotmail.com \\ ${ }^{3}$ Materials and Instrumentations group, High School of Technology, Moulay Ismail University, Morocco \\ briseddik@gmail.com \\ ${ }^{5}$ SATIE, UMR CNRS 8029, ENS Cachan, Univ. Paris Saclay, Cachan, France \\ abdelhatif.elfellahi@gmail.com
}

\begin{abstract}
In this work, we present a new design of split printed reader $\mathrm{H}$-antenna for RFID (Radio Frequency Identification) applications, at $2.45 \mathrm{GHz}$. The HFSS electromagnetic simulation software is used to optimize of geometric parameters and to determine the antenna radiation characteristics. The CST electromagnetic simulation software is also used to compare and validate the results. The results show that the reflection coefficient reaches a level of $-36 \mathrm{~dB}$ at $2.45 \mathrm{GHz}$ with a narrow bandwidth of 42 $\mathrm{MHz}$. A prototype of the antenna was produced and the experimental results show a good agreement with numerical results.
\end{abstract}

Key words : H-Antenna, HFSS, CST, Return loss, RFID

\section{INTRODUCTION}

The introduction of discontinuities in the microstrip allow it possible to improve the performances of various passive circuits, such as the improvement of the characteristics of the filters and the radiation characteristics of the patch antennas [1]-[3]. The antenna is defined as a means for radiating or receiving electromagnetic waves [4]. It therefore constitutes a transfer function between the free space and the guiding device. The antenna can therefore be used in transmission and / or reception and in this work we are interested in the study of microstrip patch antenna.

The main advantage of the use of microstrip antennas resides in their different possibilities of power supplies. The most common are microstrip line excitation [5], [6], coaxial cable [7]-[9], by opening coupling[10], [11] or by proximity coupling [12].

The patch-H antenna is widely used, notably for Bluetooth [13], WLAN [14]-[16], wireless communications [16], [17], or broadband applications [18], [19]. In this work, we have dimensioned a patch-H antenna in the UHF band for RFID applications.

We present in the second section of this article the analysis and theoretical study of the patch antenna in its rectangular basic form and the proposed patch-H structure. In the third section, we present a comparison of simulation results obtained using the two HFSS and CST software of the antenna. In the fourth section, we present the prototype realized and a comparison of experimental and simulation results.

\section{Analysis and Design of the Printed H-Antenna}

Generally, the patch antenna consists of a metal radiating plate printed on a dielectric plate of height $h$ and a ground plane printed on the other side of the dielectric [20]. The radiating plate can take several geometric shapes to meet constraints such as operating bandwidth, gain or cost. The geometry of the rectangular microstrip patch antenna is based on the procedure for performing the standard equations, proposed by E. O. Hammerstad, to determine the length $\mathrm{L}$ and the width $\mathrm{W}$ of the radiating element as well as the dimensions of the ground plane.

\section{1 Main design}

In general, rectangular patch antennas have half-wave length structures at the operating frequency of the fundamental resonance mode. This length is slightly less than half the wavelength in the material of the equivalent dielectric substrate. Therefore, the approximate value of the length of a half-wavelength path is given by[21]:

$$
L \cong 0.49 \lambda_{0} / \sqrt{\varepsilon_{e}}(1)
$$

Where $\lambda_{0}$ is the wavelength in the free space. The effective dielectric constant $\varepsilon$ e is expressed by the formula given by Hammerstad[20]:

$$
\varepsilon_{e}=\frac{\varepsilon_{r}+1}{2}+\frac{\varepsilon_{r}-1}{2}\left[1+12 \frac{\mathrm{h}}{\mathrm{W}}\right]^{-1 / 2}
$$

In this work, we used the model of the transmission line to calculate the width W. For an efficient radiator, a practical width which leads to good radiation efficiencies is given by [23]:

$$
W=\frac{c}{2 f_{r}} \sqrt{\frac{2}{\varepsilon_{r}+1}}
$$

Where $f_{0}$ is the resonance frequency of the patch antenna, $\mathrm{c}$ is the free space velocity of the light and $\varepsilon_{\mathrm{r}}$ is the relative permittivity of the dielectric.

Due to the side effects, the microstrip patch antenna is larger than its physical dimensions. The dimensions of the radiating 
part, in the direction of its length, have been extended at each end by a distance of $\Delta L . \Delta L$ is a function of the effective dielectric constant $\varepsilon_{\mathrm{r}}$ and the ratio $\mathrm{W} / \mathrm{h}$. Thus the effective corrective length, after taking the effect of the fringes, can be calculated by [21]:

$$
L=\frac{C}{2 f_{0} \sqrt{\varepsilon_{e}}}-2 \Delta L
$$

With $\Delta L$ the margin factor given by the following relation:

$$
\Delta L=0.412 h \frac{\left(\varepsilon_{r}+0.3\right)\left(\frac{w}{h}+0.264\right)}{\left(\varepsilon_{r}-0.258\right)\left(\frac{w}{h}+0.8\right)}
$$

In Fig. 1, the dimensions and the performances of the rectangular patch antenna (Fig. 1 (a)), the simple patch-H antenna (Fig. 1 (b)) and the patch-H antenna with slot and parasitic element (Fig. 1 (c)) were presented and compared in Table I. The reflection coefficient for different antennas is represented in Fig. 2. The devices shown refer to a working frequency of about $2.45 \mathrm{GHz}$ and to a standard and costeffective FR4 epoxy substrate having a thickness h.

In particular, the advantage in terms of reducing the size of the patch-H antenna with slot and parasitic element is clear. In fact, it has been shown that its size reduction compared to a rectangular patch antenna is $34 \%$; while the radiation characteristics of the antenna are well preserved.

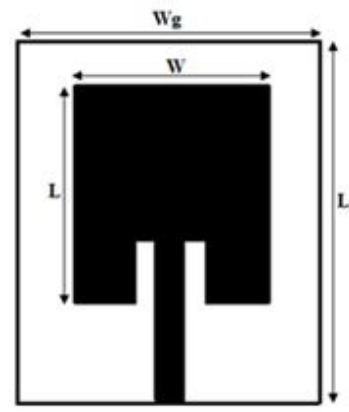

(a)

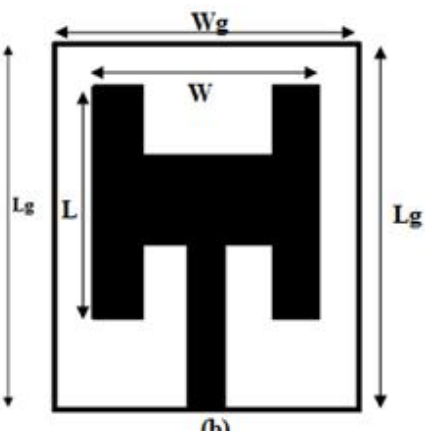

(b)

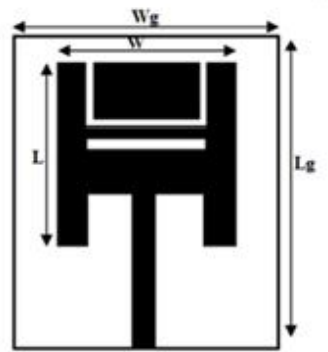

(c)

Figure 1: $\quad$ Layout for the patch antenna: (a) rectangle, (b) simple H-shape, (c) H-shape with slot and parasitic element

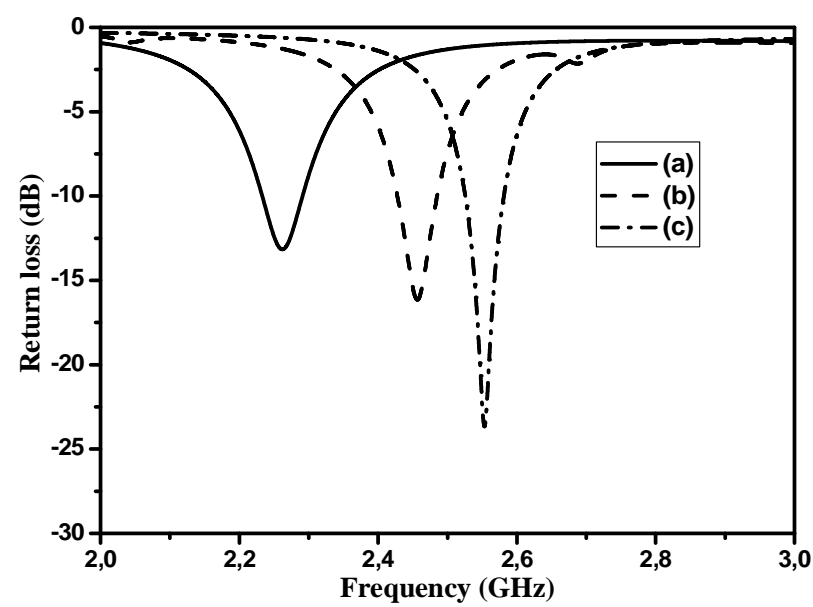

Figure 2: $\quad$ Return loss of deferent patch given in Fig. 1

Table 1:Comparison of dimensions and performance of different patch

\begin{tabular}{|c|c|c|c|c|c|c|}
\hline \multirow{4}{*}{$\begin{array}{l}\text { Patch } \\
\text { rectangular }\end{array}$} & Parameters & $\mathrm{L}_{\mathrm{g}}$ & $\mathrm{W}_{\mathrm{g}}$ & $\mathrm{L}$ & $\mathrm{W}$ & $\mathrm{h}$ \\
\hline & $\begin{array}{l}\text { Values } \\
(\mathrm{mm})\end{array}$ & 62 & 50 & 31.3 & 22 & 3 \\
\hline & S11 (dB) & \multicolumn{5}{|c|}{-13} \\
\hline & Gain $(\mathrm{dB})$ & \multicolumn{5}{|c|}{2.51} \\
\hline \multirow{4}{*}{ Simple Patch-H } & Parameters & $\mathrm{L}_{\mathrm{g}}$ & $\mathrm{W}_{\mathrm{g}}$ & $\mathrm{L}$ & $\mathrm{W}$ & $\mathrm{h}$ \\
\hline & $\begin{array}{l}\text { Values } \\
(\mathrm{mm})\end{array}$ & 60 & 48 & 33 & 21 & 1.8 \\
\hline & $\mathrm{S} 11(\mathrm{~dB})$ & \multicolumn{5}{|c|}{-16} \\
\hline & Gain (dB) & \multicolumn{5}{|c|}{1.57} \\
\hline \multirow{4}{*}{$\begin{array}{l}\text { H-shape with } \\
\text { slot and parasitic } \\
\text { element }\end{array}$} & Parameters & $\mathrm{L}_{\mathrm{g}}$ & $\mathrm{W}_{\mathrm{g}}$ & $\mathrm{L}$ & $\mathrm{W}$ & $\mathrm{h}$ \\
\hline & $\begin{array}{l}\text { Values } \\
(\mathrm{mm})\end{array}$ & 51 & 40 & 31 & 22 & 1.6 \\
\hline & S11 (dB) & \multicolumn{5}{|c|}{-22} \\
\hline & Gain $(\mathrm{dB})$ & \multicolumn{5}{|c|}{1.89} \\
\hline
\end{tabular}
antennas

\section{2 Proposed patch-H antenna}

The patch-H antenna prototype with slot and parasitic element using the FR4 epoxy substrate with a height $h=1.6$ $\mathrm{mm}$, a dielectric constant $\varepsilon_{\mathrm{r}}$ of 4.4 and a loss tangent of 0.02 is used for the design. For a good functioning, we have been able to adapt the geometry of the antenna so that it can work with optimal performance. For a better impedance matching, a simple rectangular transmission line, length $d=10 \mathrm{~mm}$ and width $\mathrm{e}=3 \mathrm{~mm}$, is introduced to excite the patch, the line is sized so that the excitation sees a characteristic impedance of $50 \Omega$ (Fig. 3). Note that the patch antenna is fed by an axial microstrip line. 


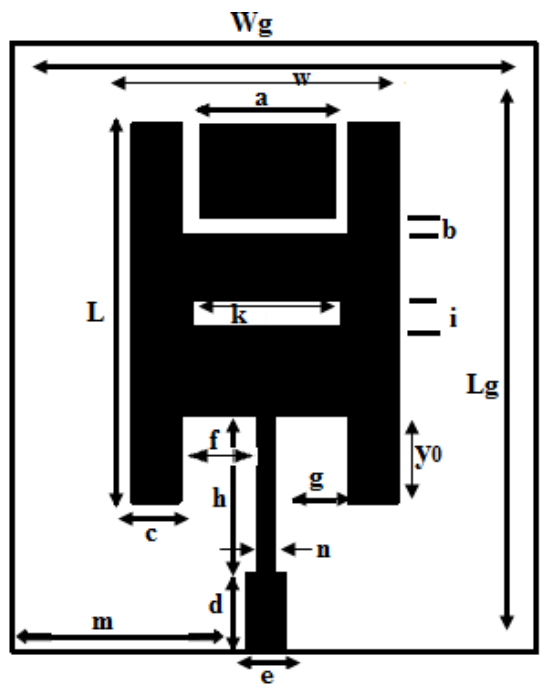

Figure 3: $\quad$ Geometry of the patch-H antenna

Figures 4 and 5 shows the return loss for different values of the slot. The parametric study shows that the resonance frequency of the antenna changes with the slits of the slit. The resonance frequency is proportional to the width of the slot and inversely proportional to the length.

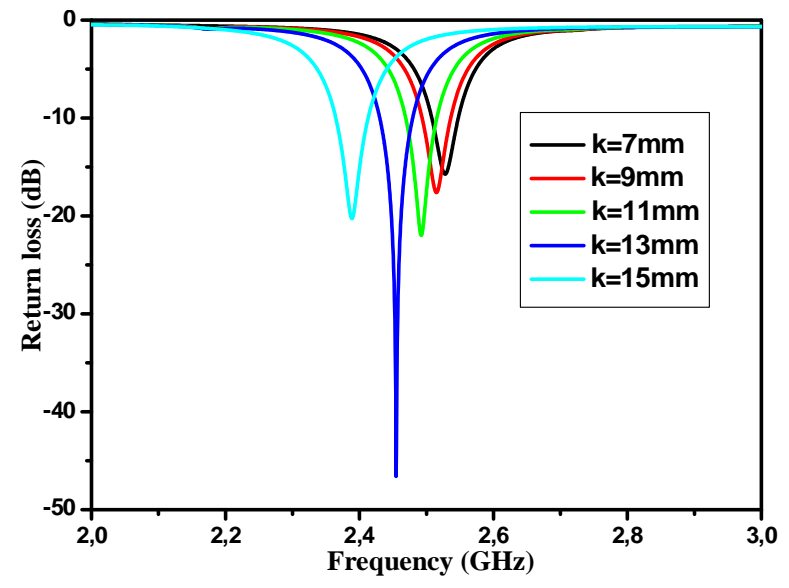

Figure 4: $\quad$ Variation of S11 according to the length of the slot

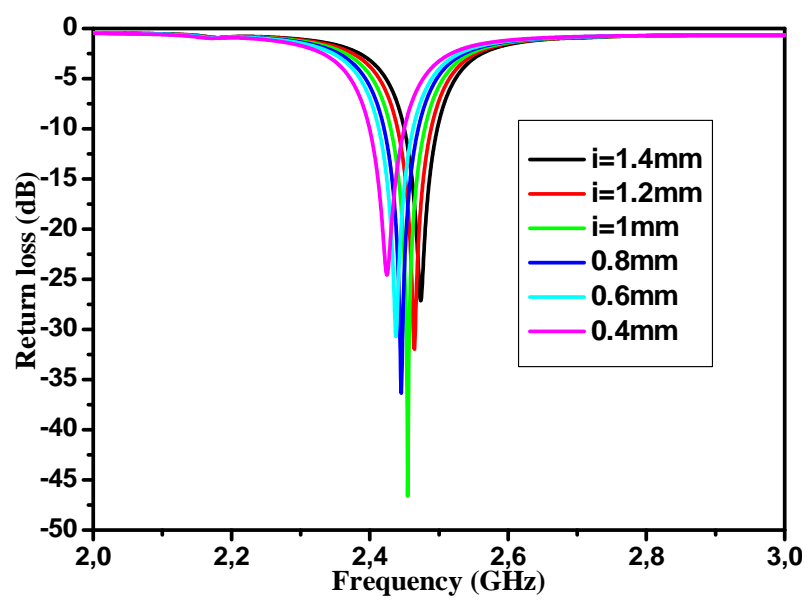

Figure 5: $\quad$ Variation of S11 according to the width of the slot
The miniaturization of the simple patch-H antenna causes a decrease in gain, to remedy this decrease in gain, a parasitic element is introduced to increase the effective surface of the proposed antenna, thus an increase in gain.

Figures 6 and 7 show the gain of the antenna with and without parasitic element. We see that the gain increases with the insertion of the parasitic element

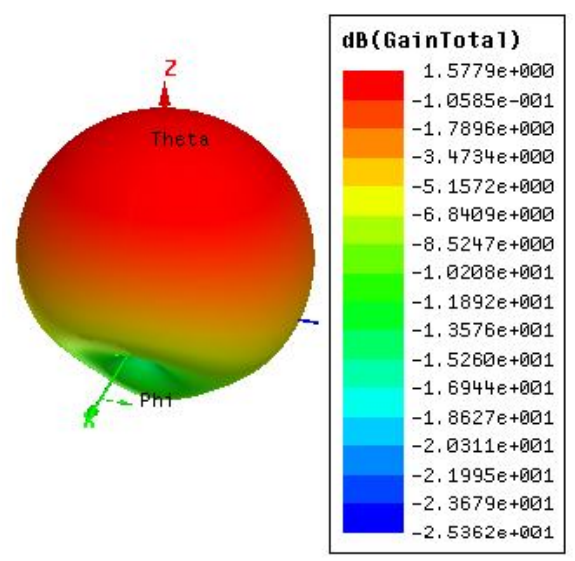

Figure 6: $\quad$ radiation pattern of the antenna without parasitic element

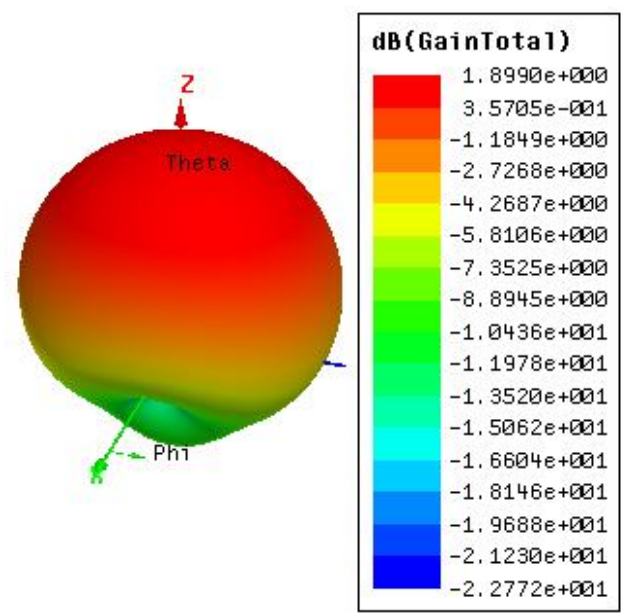

Figure 7: $\quad$ radiation pattern of the antenna with parasitic element

After an optimization using the HFSS software, the dimensions used for our patch-H antenna operating at 2.45 $\mathrm{GHz}$ are summarized in Table II.

Table 2:The Size of the base Antenna

\begin{tabular}{|c|c|}
\hline Parameters & Values (mm) \\
\hline $\mathrm{W}_{\mathrm{g}}$ & 46 \\
\hline $\mathrm{L}_{\mathrm{g}}$ & 51 \\
\hline $\mathrm{L}$ & 34 \\
\hline $\mathrm{W}$ & 20 \\
\hline $\mathrm{a}$ & 12 \\
\hline $\mathrm{b}$ & 1 \\
\hline $\mathrm{c}$ & 3 \\
\hline
\end{tabular}


A.Bendali et al., International Journal of Advanced Trends in Computer Science and Engineering, 9(1.5), 2020,41 - 45

\begin{tabular}{|c|c|}
\hline $\mathrm{e}$ & 3 \\
\hline $\mathrm{f}$ & 5 \\
\hline $\mathrm{d}$ & 10 \\
\hline $\mathrm{Y}_{0}$ & 11 \\
\hline $\mathrm{h}$ & 11.5 \\
\hline $\mathrm{i}$ & 1 \\
\hline $\mathrm{g}$ & 6.4 \\
\hline $\mathrm{k}$ & 13 \\
\hline $\mathrm{n}$ & 2.6 \\
\hline $\mathrm{m}$ & 21 \\
\hline
\end{tabular}

Figure 9: $\quad$ Evolution of the reflection coefficient as a function of frequency

The ratio of standing waves as a function of frequency is shown in fig. 10. The VSWR is of the order of 1.006 at the frequency $\mathrm{f}_{0}=2.45 \mathrm{GHz}$ which shows that the maximum power is transmitted to the antenna at this frequency. We can note that the result obtained by HFSS is confirmed by the simulator CST.

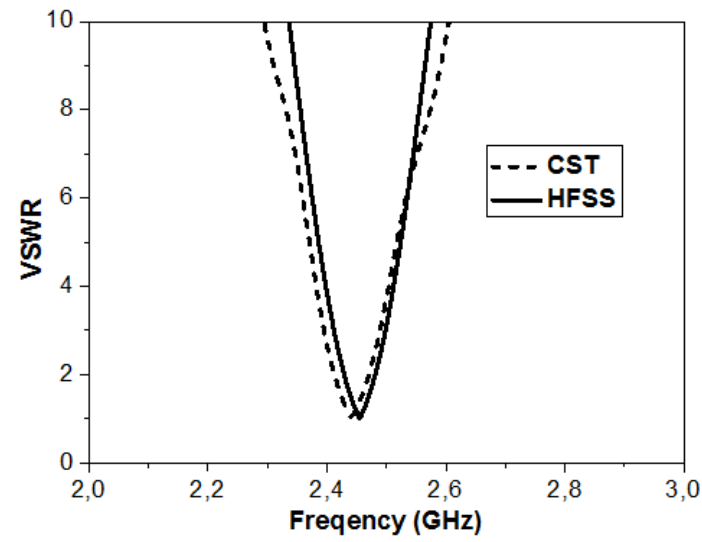

Figure 10: $\quad$ Stationary wave ratio

The fig. 8 shows the evolution of the simulation reflection coefficient as a function of the frequency.

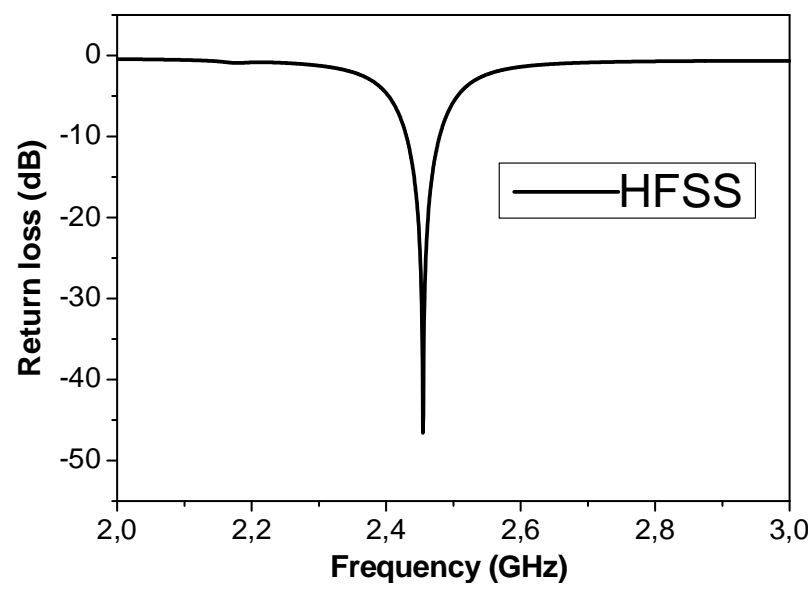

Figure 8: $\quad$ Evolution of the return loss as a function of frequency

\section{Simulated ANd Measured Results}

The simulation and the comparison of the evolution of the reflection coefficient obtained through the simulation software HFSS and CST of the antenna are given in fig.9. The results obtained show a good agreement between the two simulation software. It is also noted that the antenna can operate at the operating frequency $\mathrm{f}_{0}=2.45 \mathrm{GHz}$ with a bandwidth of $49 \mathrm{MHz}$.

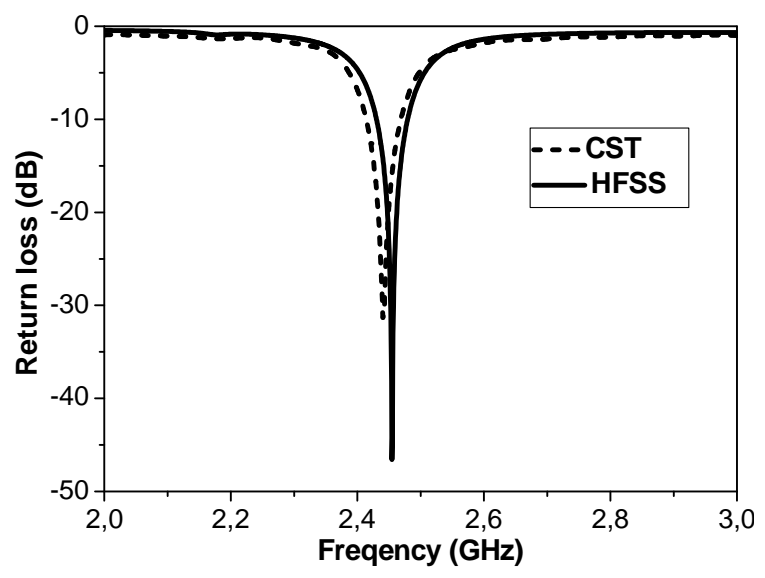

The fig.11 shows the evolution of the input impedance of the patch-H antenna as a function of the frequency. Note that the impedance is equal to $\mathrm{Zin}=(49.32-\mathrm{j} 0.95) \Omega$ at the frequency of $2.45 \mathrm{GHz}$. The resistive part of the input impedance of the antenna is very close to the output resistance of the power source and the imaginary part is almost zero.

After that, we focus on the gain of the antenna. It represents the ratio between the power radiated in a given direction and the power that would be radiated by the isotropic antenna having the same losses. The radiation pattern of this antenna is shown in fig. 12.

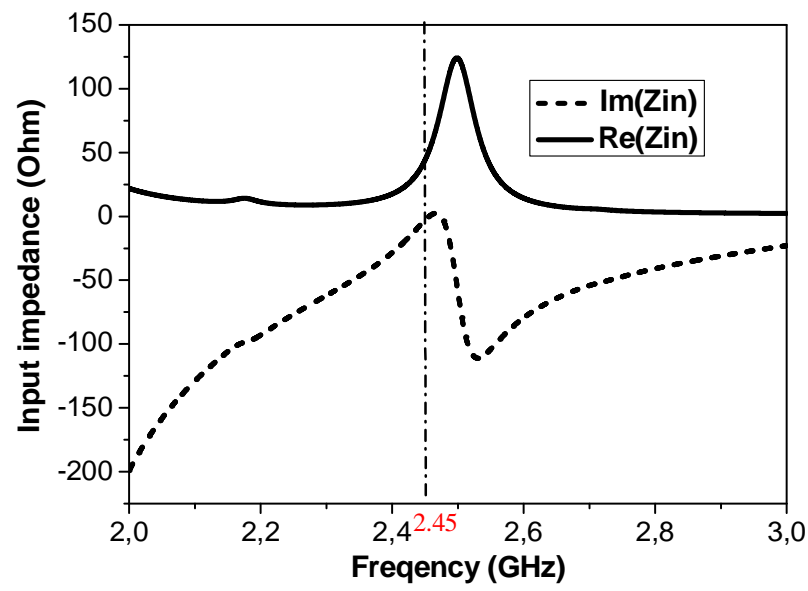


Figure 11: $\quad$ Evolution of input impedance Zin as a function

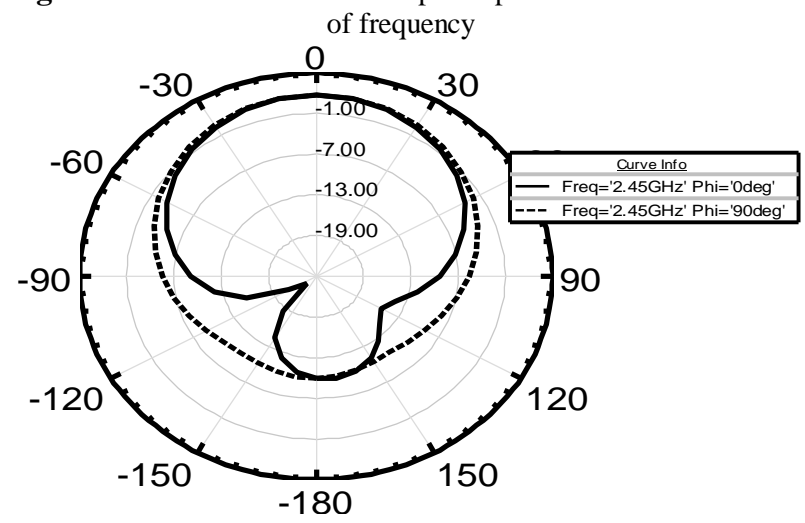

Figure 12: $\quad$ Radiation pattern of the proposed antenna at

$$
2.45 \mathrm{GHz}
$$

The fig. 13 shows the 3D radiation patterns obtained by the two HFSS and CST. This figure shows that the two simulators have the same gain with a deviation of $0.83 \mathrm{~dB}$.

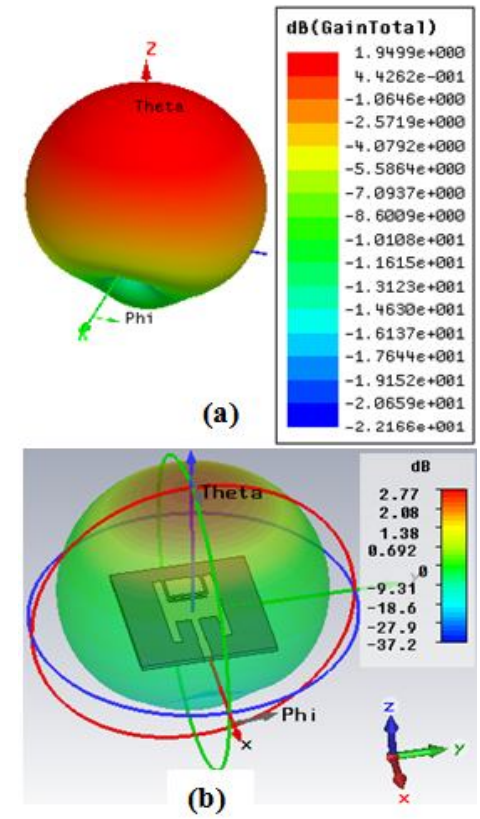

Figure 13: $\quad 3$ radiation pattern obtained by HFSS (a) and by CST (b)

Given this very encouraging performance, in the following part we are interested to the realization of a prototype.

A prototype of the patch-H microstrip antenna was manufactured using an ER4 epoxy substrate with a relative dielectric constant of 4.4 and a thickness of $1.6 \mathrm{~mm}$. Fig.14a shows a photograph of the antenna after realization by chemical etching. The test bench is given in fig. $14 \mathrm{~b}$. The characteristics of the antenna are measured by a Vectorial Network Analyzer (VNA E5061B). The measurements were carried out in the frequency range 2 to $3 \mathrm{GHz}$.

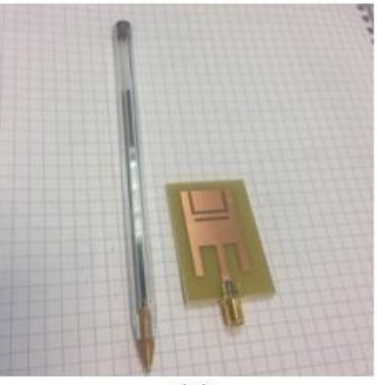

(a)

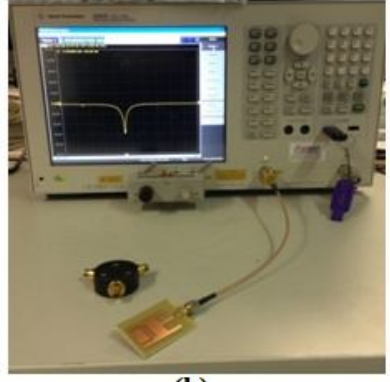

(b)
Figure 14: $\quad$ Set up description. (a) Photography of the realized antenna. (b) Test bench

The frequency dependence of the reflection coefficient is given in fig.15. A superimposition of these experimental data and the simulated data is also given. These results show good agreement between simulation and measurement. In the same way, we find an operating frequency $\mathrm{fO}=2.45 \mathrm{GHz}$ with a bandwidth of $42 \mathrm{MHz}$.

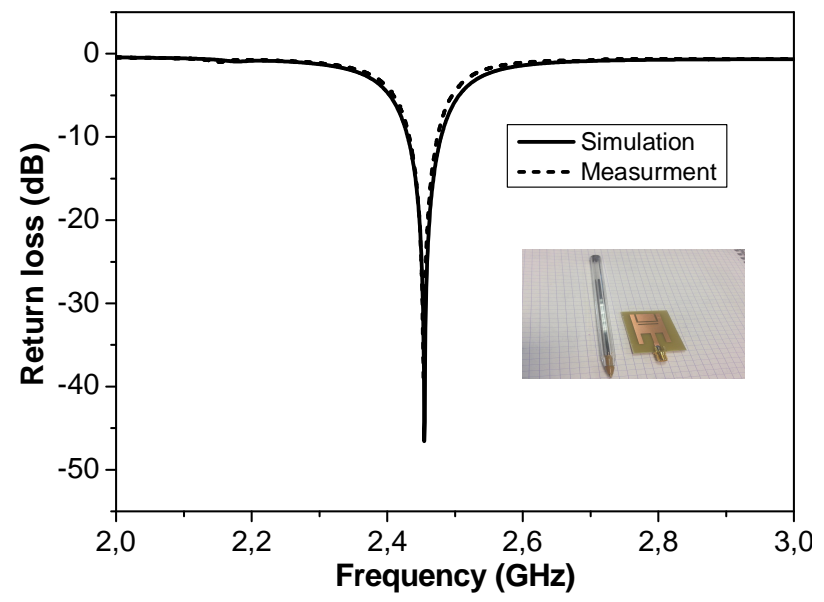

Figure 15: $\quad$ Comparison between simulation and measure

\section{CONCLUSION}

In this work, a new H-shape patch antenna structure has been proposed. After an optimal geometrical dimensioning of the antenna by using the simulation software HFSS and CST, a stationary wave rate of less than 1.5 and a gain of $1.95 \mathrm{~dB}$ are deduced. In addition, the experimental results showed a reflection coefficient $\mathrm{S} 11$ equal to $-36 \mathrm{~dB}$ at the frequency of $2.45 \mathrm{GHz}$ with a bandwidth of $42 \mathrm{MHz}$ to $-10 \mathrm{~dB}$.

\section{REFERENCES}

1. I. Tabakh, M. Jorio, N. E. A. El Idrissi, and T. Mazri. Design and simulation of an optimized slotted patch antenna for RFID reader applications, in Information Technology for Organizations Development (IT4OD), 2016 International Conference on, 2016, pp. 1-6.

2. N. Singh and A. Kumar. Design and Performance Analysis of a Novel High Gain and Compact Planar Patch Antenna for RFID Reader Application, in Micro-Electronics and Telecommunication Engineering (ICMETE), 2016 International Conference on, 2016, pp. 78-83.

3. S. LAKRIT, H. AMMOR, J. TERHZAZ, and A. TRIBAK. Design of a new high-gain multiband and wideband rectangular patch antenna for $\mathrm{C}, \mathrm{X}$, and 
Ku band applications, Walailak J. Sci. Technol., vol. 14, no. 4, pp. 339-351, 2016.

4. C. Ryan and L. Peters. Evaluation of edge-diffracted fields including equivalent currents for the caustic regions, IEEE Trans. Antennas Propag., vol. 17, no. 3, pp. 292-299, 1969.

5. E. Hanae, N. Amar Touhami, and M. Aghoutane. Miniaturized microstrip patch antenna with spiral defected microstrip structure, Prog. Electromagn. Res., vol. 53, pp. 37-44, 2015.

6. E. Hanae, N. Amar Touhami, M. Aghoutane, S. El Amrani, A. Tazon, and M. Boussouis. Miniaturized microstrip patch antenna with defected ground structure, Prog. Electromagn. Res., vol. 55, pp. 25-33, 2014.

7. S. Das, P. P. Sarkar, and S. K. Chowdhury. Design and analysis of a compact triple band slotted microstrip antenna with modified ground plane for wireless communication applications, Prog. Electromagn. Res., vol. 60, pp. 215-225, 2014.

8 F. Jolani, A. M. Dadgarpour, and H. R. Hassani. Compact M-slot folded patch antenna for WLAN, Prog. Electromagn. Res., vol. 3, pp. 35-42, 2008.

9. S.-J. Wang, L. Li, and M. Fang. A novel compact differential microstrip antenna, Prog. Electromagn. Res., vol. 57, pp. 97-101, 2015.

10. A. Ittipiboon, R. Oostlander, Y. M. M. Antar, and M. Cuhaci. A modal expansion method of analysis and measurement on aperture-coupled microstrip antenna, IEEE Trans. Antennas Propag., vol. 39, no. 11, pp. 1567-1574, 1991.

11. K. Swamy and M. Veluri. Active integrated antenna (AIA) system for wireless communication, Int. J. Sci. Res. Publ., vol. 3, no. 11, pp. 1-5, 2013.

12. P. S. Bakariya, S. Dwari, M. Sarkar, and M. K. Mandal. Proximity-coupled microstrip antenna for bluetooth, WiMAX, and WLAN applications, IEEE Antennas Wirel. Propag. Lett., vol. 14, pp. 755-758, 2015.

13. A. Majumder. Design of an h-shaped microstrip patch antenna for bluetooth applications, Int. J. Innov. Appl. Stud., vol. 3, no. 4, pp. 987-994, 2013.
14. D. Pavithra and K. R. Dharani. A design of H-shape Microstrip patch antenna for WLAN applications, IJESI, ISSN, pp. 2319-6734, 2013.

15. M. TARBOUCH, A. EL AMRI, and $\mathrm{H}$. TERCHOUNE. Design, Realization and Measurements of Compact CPW-Fed Microstrip Octagonal Patch Antenna with H Slot for WLAN and WIMAX Applications, Int. J. Electr. Comput. Eng., vol. 12, no. 5, pp. 389-398, 2017.

16. M. Tarbouch, A. El Amri, and H. Terchoune. Design, Realization and Measurements of Compact Dualband CPW-fed Patch Antenna for 2.45/5.80 GHz RFID Applications, Int. J. Electr. Comput. Eng., vol. 8, no. 1, pp. 172-178, 2018.

17. V. Subba Reddy, M. Siva Ganga Prasad, B T P Madha. Design of a Koch Shaped Fractal Antenna for Wireless Applications, International Journal of Advanced Trends in Computer Science and Engineering, vol. 8, no. 4, pp. 1674-1678, 2019.

18. M. Munir, A. Altaf, and M. Hasnain. Miniaturization of microstrip fractal $\mathrm{H}$-Shape patch antenna using stack configuration for wireless applications, in Recent Trends in Information Systems (ReTIS), 2015 IEEE 2nd International Conference on, 2015, pp. 44 48.

19. V. Subba Reddy, M. Siva Ganga Prasad, B T P Madha. Design and Implementation of Dual Notch Band Characteristics in UWB Antenna for Wireless Personal Communications, International Journal of Advanced Trends in Computer Science and Engineering, vol. 8, no. 4, pp. 1719-1725, 2019.

20. C. A. Balanis. Antenna theory: analysis and design, John wiley \& sons, 2016.

21. I. J. Bahl and P. Bhartia. Microstrip antennas, Artech house, 1980.

22. E. O. Hammerstad. Equations for microstrip circuit design, Microwave Conference, 1975. 5th European, 1975, pp. 268-272.

23. W. L. Stutzman and G. A. Thiele. Antenna theory and design, John Wiley \& Sons, 2013. 